\begin{tabular}{|c|c|c|c|c|}
\hline Jurnal Penelitian \& PKM & Juli 2017 & Vol 4, No: 2 & Hal: $129-389$ & $\begin{array}{c}\text { ISSN } \\
2442-448 X(p), 2581-1126(e)\end{array}$ \\
\hline
\end{tabular}

\title{
PENGUATAN KELEMBAGAAN KOPERASI BAGI PETANI KOPI DAN TEMBAKAU DI DESA GENTENG KECAMATAN SUKASARI KABUPATEN SUMEDANG
}

\author{
OLEH: \\ MEILANNY BUDIARTI SANTOSO ${ }^{1}$, SAHADI HUMAEDI ${ }^{2}$, NURLIANA CIPTA APSARI ${ }^{3}$, SANTOSO TRI RAHARJO ${ }^{4}$ \\ 1. Pusat Studi Kewirausahaan Sosial, CSR, dan Pengembangan Masyarakat Fakultas IImu Sosial dan Ilmu Politik Universitas Padjadjaran \\ 2. Pusat Studi Kewirausahaan Sosial, CSR, dan Pengembangan Masyarakat Fakultas IImu Sosial dan IImu Politik Universitas Padjadjaran \\ 3. Pusat Studi Kesejahteraan Anak dan Keluarga Fakultas IImu Sosial dan Ilmu Politik Universitas Padjadjaran \\ 4. Pusat Studi Kewirausahaan Sosial, CSR, dan Pengembangan Masyarakat Fakultas Ilmu Sosial dan Ilmu Politik Universitas Padjadjaran
}

\section{Email:}

(meilannybudiarti13@gmail.com ${ }^{1}$, sahadi.humaedi@unpad.ac.id²,nurliana.apsari@gmail.com³ santoso.tri.raharjo@unpad.ac.id $d^{4)}$

\begin{abstract}
Abstrak
Kegiatan penguatan kelembagaan koperasi bagi petani kopi dan tembakau di Desa Genteng Kecamatan Sukasari Kabupaten Sumedang ini dilatarbelakangi oleh keberadaan koperasi di Desa Genteng yang belum sepenuhnya berfungsi bagi warga masyarakat dan belum dimanfaatkan secara optimal oleh warga sekitar. Hal tersebut disebabkan oleh karena masyarakat yang belum mengetahui manfaat dari koperasi itu sendiri. Masyarakat juga hanya mengetahui satu fungsi koperasi yaitu untuk memberikan bantuan modal dalam bentuk uang. Padahal terdapat beberapa fungsi lainnya dari koperasi, diantaranya yaitu untuk mengembangkan potensi warga masyarakat dan daerah sekitar, serta dapat menjadi wahana untuk meningkatkan kemampuan ekonomi anggota koperasi dan juga masyarakat secara umum. Berdasarkan situasi tersebut, maka diperlukan berbagai upaya untuk meningkatkan pengetahuan pada masyarakat tentang keberadaan dan fungsi koperasi di Desa Genteng, dengan tujuan agar para petani kopi dan tembakau dapat memanfaatkan keberadaan koperasi tersebut secara optimal.
\end{abstract}

Kata kunci: Koperasi, Petani Kopi, Penguatan Kelembagaan, Koperasi Desa

\section{Abstract}

Activities of strenghtening the cooperative institutional for farmers of coffee and tobacco at Genteng Village on Sukasari District in Sumedang Regency, is supported by the presence of the cooperatives in Genteng Village that has not been fully functioning yet by the local residents. It happened because the community still do not know about the benefits of the cooperative itself. Besides that, they also know only one function of cooperatives which is to provide capital assistance in the form of cash. Whereas, there are some other functions of cooperatives such as in developing the potential things of each residents and it surroundings. It also can be a way to improve the economic 
rates for the members and the communities in general as well. Based on the situation, so that required measures to increase knowledge to the community about the availability and the function of cooperatives in Genteng Village, in order to create the farmers of coffee and tobacco can use these cooperatives optimally.

Keywords: Cooperative, Farmer of Coffee, Institutional Strengthening, Village Cooperatives

\section{Pendahuluan}

Desa Genteng, Kecamatan Sukasari, Kabupaten Sumedang, merupakan daerah pegunungan dan perbukitan, termasuk dalam kategori dataran tinggi dengan ketinggian tempat 800-1200 mdpl. Salah satu potensi yang dimiliki oleh Desa Genteng adalah pada sektor perkebunan yaitu kebun kopi dan tembakau, yang telah menjadi mata pencaharian utama masyarakat sekaligus menjadi roda penggerak perekonomian dalam menopang kehidupan bermasyarakat.

Aktivitas perkebunan dan pengolahan kopi sudah ada sejak tanggal 10 Desember 2009 hingga sekarang, yang dikoordinasikan oleh Koperasi Berdikari. Koperasi Berdikari telah menanam kurang lebih 14.700 bibit kopi varietas arabica Kartika I. Penanaman dilakukan di atas ketinggian $1200 \mathrm{mdpl}$, di kaki gunung Cijambu. Di samping itu, saat ini, Koperasi Berdikari sedang melaksanakan program Pembibitan kopi varietas arabica sama sebanyak 300.000 bibit. Program penanaman bibit kopi varietas arabica ini telah berhasil memobilisasi kurang lebih 500 (lima ratus) petani penggarap di sekitar kaki gunung Cijambu. Aktivitas penanaman serta pengolahan kopi ini merupakan salah satu kegiatan perekoomian penopang penghasilan warga, terutama warga di Dusun I Desa Genteng, Kecamatan Sukasari Kabupaten Sumedang.

Namun demikian, terdapat permasalahan yang dihadapi oleh para petani, yaitu bahwa para petani kopi dan tembakau ini masih kebingungan dalam mengelola hasil kopi dan tembakau. Akhirnya petani terpaksa menjual hasil panennya ke tengkulak/pengepul kopi dan tembakau, tentunya dengan harga jual yang murah dan hal ini sangat merugikan petani kopi dan tembakau.

Situasi tersebut menunjukkan bahwa keberadaan koperasi di Desa Genteng belum sepenuhnya berfungsi bagi warga masyarakat dan belum dimanfaatkan secara optimal oleh warga sekitar. Hal tersebut disebabkan oleh masyarakat yang belum mengetahui manfaat dari koperasi itu sendiri. Masyarakat juga hanya mengetahui satu fungsi koperasi yaitu untuk memberikan bantuan modal dalam bentuk uang. Padahal ada beberapa fungsi lain dari koperasi, diantaranya untuk mengembangkan potensi warga masyarakat dan daerah sekitar serta dapat menjadi wahana untuk meningkatkan kemampuan ekonomi anggota keperasi dan juga masyarakat secara umum. Kinerja koperasi pun dapat mempertinggi kualitas kehidupan masyarakat, memperkokoh perekonomian rakyat, mengembangkan perekonomian nasional, serta mengembangkan kreativitas dan jiwa berorganisasi bagi masyarakat.

Seharusnya, bagi para petani kopi dan tembakau di wilayah Desa Genteng sendiri, keberadaan koperasi dapat bermanfaat dalam hal pemasaran hasil kebun dari para anggotanya dengan harga jual yang lebih tinggi dan pengadaan kebutuhan konsumsi dengan harga yang lebih murah atau stabil. Sayangnya berbagai manfaat dari keberadaan koperasi tersebut selama ini belum 
teraktualisasikan dengan baik, hanya dapat dinikmati oleh beberapa orang anggotanya saja dan itu pun masih sangat terbatas, sedangkan bagi masyarakat secara luas keberadaan koperasi belum dimanfaatkan dengan baik.

Berdasarkan situasi tersebut di atas, maka upaya upaya meningkatkan pengetahuan masyarakat terkait keberadaan koperasi di Desa Genteng menjadi hal yang penting untuk dilakukan, agar para petani kopi dan tembakau khususnya juga masyarakat luas pada umumnya dapat secara optimal memanfaatkan keberadaan koperasi. Di sisi lain, kapasitas kelembagaan koperasi pun perlu ditingkatkan agar dapat menjangkau masyarakat lebih luas lagi dan dapat berkinerja dengan lebih baik lagi.

\section{Metode}

\section{Kegiatan pelatihan diselenggarakan} dalam rangka penguatan kelembagaan koperasi di Desa Genteng. Pelatihan ini ditujukan bagi para petani kopi, petani tembakau, pengurus keorganisasian koperasi dan juga bagi inisiator koperasi desa. Metode yang dilakukan dalam pelatihan ini adalah metodologi pelatihan andragogi, yang mensyaratkan peserta pelatihan diposisikan sebagai orang dewasa dan didorong untuk berperan aktif dalam setiap tahapan pelatihan. Baik melalui metode brainstrorming menganai permasalahan yang dihadapi dan juga metode sharing pengalaman diantara sesama peserta pelatihan dan juga dari fasilitator pelatihan. Hal ini bertujuan agar peserta pelatihan dapat melihat segala sesuatu terkait dengan permasalahan yang sedang dihadapi dari sudut pandang yang berbeda dan kemudian secara bersama-sama mencari dan menetapkan solusi untuk permasalahan yang dihadapi tersebut.

\section{Pembahasan}

1. Analisis Situasi Kewilayahan Desa Genteng
Secara administratif Desa Genteng merupakan salah satu dari 7 Desa di Wilayah Kecamatan Sukasari Kabupaten Sumedang yang terletak $3 \mathrm{Km}$ ke arah Utara dari Kecamatan Sukasari. Desa Genteng berada di ketinggian 1200 diatas permukaan laut dengan wilayah \pm 1300 Hektar. Desa Genteng berbatasan dengan beberapa desa yaitu:

- Sebelah Barat berbatasan dengan desa Banyuresmi

- Sebelah Timur berbatasan dengan desa Kadakjaya

- Sebelah Selatan berbatasan dengan desa Sukasari

- Sebelah Utara berbatasan dengan desa Kehutanan

Suhu di daerah Desa Genteng berkisar di angka $30^{\circ} \mathrm{C}$ dengan mengalami dua cuaca, yaitu kemarau dan penghujan. Hal tersebut mempunyai pengaruh langsung terhadap pola tanam yang ada di Desa Genteng dan sangat berpengaruh terhadap pertumbuhan tanaman dan kelangsungan hidup binatang ternak. Selain itu, kondisi geografis desa Genteng umumnya merupakan perbukitan.

Masyarakat Desa Genteng memiliki keterampilan dalam pengelolaan sumber daya alam berupa bertani kopi, tembakau, dan sayuran organik serta beternak dan membuat kerajinan bambu. Bila ditinjau dari tingkat pendidikan masyarakat, mayoritas penduduk Desa Genteng berpendidikan Sekolah Dasar dengan jumlah 921 orang di tahun 2015. Desa Genteng merupakan desa yang mempunyai jumlah penduduk 6139 jiwa, 2219 KK yang terbagi kedalam 6 dusun, 19 RW dan 76 RT.

Karakteristik masyarakat Desa Genteng diwarnai oleh pola pikir tokoh-tokoh desa sebagai panutan bagi masyarakat desa. Beberapa tokoh desa yang dikenal dan dihargai oleh masyarakat Desa Genteng diantaranya adalah tokoh agama, tokoh pemuda, pengusaha kopi, bapak kuwu (Kepala Desa) dan staf pemerintahan desa lainnya, ketua pengrajin bambu, serta para kepala dusun. 
Sebagian besar lahan di Desa Genteng digunakan untuk lahan pemukiman dan pertanian. Mayoritas penduduk menggunakan lahan pertanian untuk penanaman kopi dan tembakau. Dalam hal transportasi, mayoritas masyarakat Desa Genteng menggunakan sarana transportasi publik seperti angkutan umum dan ojeg, selain dari itu masyarakat menggunakan mobil pribadi ataupun motor.

Desa Genteng memiliki potensi yang cukup besar, baik dari sumber daya manusia maupun sumber daya alam. Salah satu potensi dalam sumber daya alam yang terdapat di Desa Genteng adalah ketersediaan kopi dan tembakau. Namun, berdasarkan data RPJM Desa Genteng (2016), sampai saat ini potensi sumber daya belum benar-benar optimal diberdayakan. Hambatan yang dihadapi oleh masyarakat Desa Genteng adalah kurangnya pengetahuan dan kecakapan khusus pada diri masyarakat dalam pengelolaan sumber daya alam.

\section{Pelatihan Penguatan Kelembagaan Koperasi}

Dalam mengikuti kegiatan pelatihan, para peserta berpartisipasi aktif dalam kegiatan pelatihan dan menjalani setiap tahapan kegiatan dengan baik serta antusias. Hal ini ditunjukkan dari banyaknya peserta yang terlibat dalam diskusi dan tanya jawab.

Terkait dengan tatanan kelembagaan koperasi, masalah serius yang perlu mendapatkan perhatian adalah soal ketidakjelasan pembagian wewenang antara berbagai kelengkapan organisasi koperasi. Sebagaimana diketahui, tatanan kelembagaan koperasi dalam garis besarnya terdiri atas: fungsi pengurus, fungsi pengawas dan fungsi manajer serta karyawan koperasi. Dalam praktek yang berlangsung selama ini pelaksanaan fungsifungsi pokok organisasi koperasi itu cenderung tumpang tindih. Dalam kaitannya dengan fungsi manajerial misalnya, walaupun secara yuridis keberadaan manajer dalam struktur kelembagaan koperasi dinyatakan sebagai pembantu pengurus (UU No. 25 / 1992), namun manajer sebenarnya dapat diberi wewenang secara luas. Dengan seijin pengurus, manajer sebenarnya dapat mengambil alih hampir semua fungsi yang kini dijalankan oleh pengurus (Ranupandojo, 1992).

Koperasi mempunyai karakteristik khusus ditinjau dari keangotaannya yaitu anggota sebagai pemilik (owner) sekaligus anggota sebagai pengguna jasa koperasi (user), yang lebih dikenal dengan prinsip "dual identity' anggota. Agar koperasi dapat berfungsi dengan baik, maka "dual identity' anggota harus dilaksanakan dengan baik. Pencerminan sifat ganda anggota tersebut juga nampak pada kelembagaan koperasi.

Menurut Subyantoro (2008) bahwa dalam kelembagaan koperasi terdapat dua peran yang mendukung kelembagaan koperasi, yaitu peran kelembagaan kelompok berkoperasi (cooperative group) dan peran kelembagaan usaha (cooperative enterprise). Kedua kelompok tersebut merupakan pencerminan dua sifat ganda anggota koperasi yaitu anggota sebagai pemilik sekaligus pelanggan. Sehingga kualitas kelembagaan koperasi akan sangat dipengaruhi oleh kualitas partisipasi anggota koperasi. Kualitas partisipasi anggota koperasi ditentukan oleh faktor intern dan ekstern koperasi sebagai berikut:

1) Faktor Intern

Pengurus dan pengawas koperasi yang lemah, hal ini disebabkan dipilihnya pengurus/pengawas yang tidak memenuhi kualifikasi, sehingga kurang berfungsi sebagaimana mestinya. Kualitas pelaksanaan Rapat Anggota Tahunan (RAT) yang lemah. RAT merupakan pencerminan demokrasi ekonomi. Kebanyakan anggota pasif sehingga RAT akhirnya hanya didominasi oleh sekelompok orang tertentu. Hal ini disebabkan kesadaran anggota yang masih rendah dan kegiatan usaha koperasi yang tidak 


\begin{tabular}{|c|c|c|c|c|}
\hline Jurnal Penelitian \& PKM & Juli 2017 & Vol 4, No: 2 & Hal: $129-389$ & $\begin{array}{c}\text { ISSN } \\
2442-448 X(\mathrm{p}), 2581-1126(\mathrm{e})\end{array}$ \\
\hline
\end{tabular}

dilandaskan pada kepentingan ekonomi anggota, sehingga partisipasi anggota lemah.

\section{2) Faktor Ekstern}

Kelemahan koperasi antara lain terletak pada kerjasama antara koperasi dengan non koperasi. Koperasi harus mampu memanfaatkan strategi 3C, yaitu Customer, Cooperative dan Competition. Interaksi diantara ketiga unsur dalam strategi 3C tersebut tergambar sebagai berikut:

Gambar 1

Strategic Triangle (Ropke, 1992)

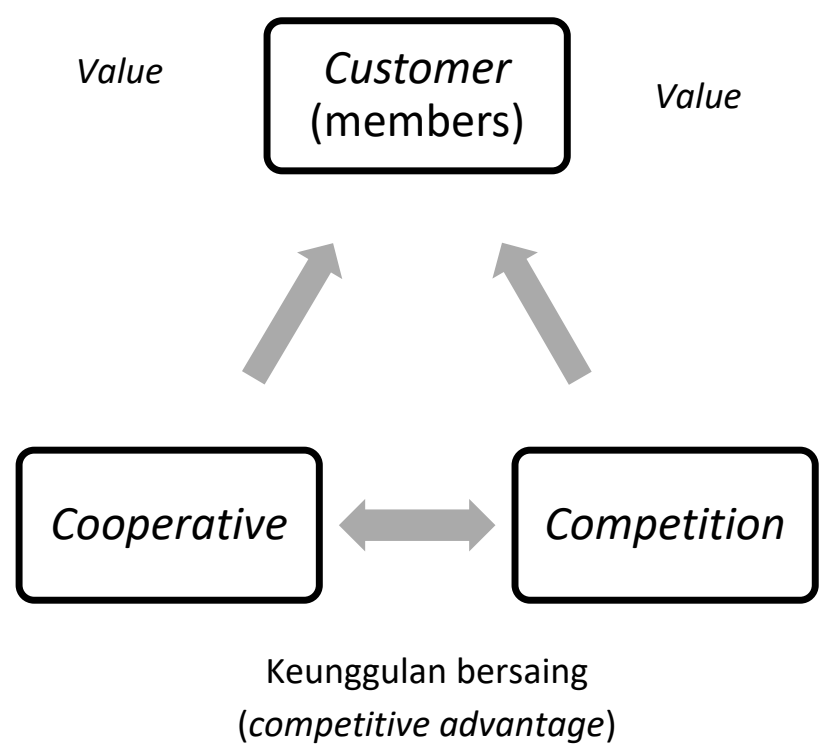

Artinya koperasi dalam menghadapi pesaingnya (non koperasi) harus mampu menciptakan nilai lebih dalam melayani anggota. Dalam menghadapi pesaing, koperasi harus mampu mewujudkan LAC (long average cost) yang berada di bawah LAC Non Koperasi (gambar 1), sehingga koperasi akan lebih unggul. (Ropke, 1992)

\section{Simpulan}

Dengan diselenggarakannya kegiatan pelatihan penguatan kelembagaan koperasi bagi petani kopi dan tembakau di Desa Genteng, telah memberi pengaruh positif bagi warga masyarakat setempat. Hal ini ditunjukkan oleh hasil pre-test dan post-test dalam pelaksanaan pelatihan yang menyatakan bahwa peserta pelatihan telah mengalami perubahan pengetahuan dan wawasan terkait kelembagaan koperasi dan keorganisasian koperasi. Sebagian besar peserta pelatihan mengemukakan bahwa pelatihan mengenai penguatan kelembagaan koperasi baru pertama kali diselenggarakan di desa mereka dan hal ini dinilai tepat karena dapat memberikan pengetahuan dan wawasan tambahan bagi masyarakat.

\section{Daftar Pustaka}

Raharjo, S. T. et.al., 2016, Penguatan Koperasi Melalui Pelatihan Pengelolaan Organisasi Di Desa Genteng, Kecamatan Sukasari, Kabupaten Sumedang, Laporan PPM Prioritas, FISIP Unpad.

Raharjo, ST. 2015. Assessment untuk Praktik Pekerjaan Sosial dan Kesejahteraan Sosial. Bandung: Unpad Press , 2015. Dasar Pengetahuan Pekerjaan Sosial. Bandung: Unpad Press. 2015. Keterampilan Pekerjaan Sosial: Dasar-dasar. Bandung, Unpad Press.

Ranupandojo, Heidjirachman. 1992. Aspek Kelembagaan Koperasi. Makalah Seminar FE UGM - DEPKOP. Yogyakarta.

Rencana Pembangunan Jangka Menengah Desa 2011-2015. Desa Genteng, Kecamatan Sukasari, Kabupaten Sumedang. 2011.

Retnowati, Daru, 2009, Strategi Pengembangan Kelembagaan Dan Koperasi Melalui Sistem Demokrasi Di Indonesia, Yogyakarta: UPN Veteran.

Ropke, Jochen. 1992. The Economic Theory of Cooperative Enterprise in Developping Countries. Marburg. 